SHORT REPORT

\title{
Value structure and priorities: Other-report account
}

\author{
Ewa Skimina $^{C, D, E, F}$, fan Cieciuch ${ }^{A, B, E, G}$ \\ Cardinal Stefan Wyszyński University in Warsaw, Warsaw, Poland
}

BACKGROUND

The aim of this study was to examine the Schwartz model of values in other-report data. We specifically tested the circular structure and priorities of personal values observed in ratings made by well-acquainted informants.

PARTICIPANTS AND PROCEDURE

We analysed self- and other-reports of preferences of 19 basic and four higher-order values provided by 422 participants $\left(M_{\text {age }}=30.02, S D_{\text {age }}=13.99\right)$ using the Portrait Value Questionnaire (PVQ-5x).

\section{RESULTS}

The self-other agreement corrected for measurement bias ranged from .29 to .78 for basic values and from .51 to .67 for higher-order values. The findings indicated that basic values measured via other-reports form a circular structure consistent with the Schwartz theory. The hierarchy of values based on other-reports only slightly differed from the hierarchy based on self-reports.

\section{CONCLUSIONS}

The results suggest that both self- and other-ratings of personal values yield meaningful information that contributes to each.

\section{KEY WORDS}

personal values; circular structure; other-reports; self-other agreement

CORResponding AUthor - Ewa Skimina, Cardinal Stefan Wyszyński University in Warsaw, 1/3 Wóycickiego Str., bldg. 14, 01-938 Warsaw, Poland, e-mail: ewa.skimina@gmail.com

AUthors' CONTRIBUtion - A: Study design - B: Data collection - C: Statistical analysis - D: Data interpretation .

E: Manuscript preparation · F: Literature search · G: Funds collection

to CITE this ARTICLE - Skimina, E., \& Cieciuch, J. (2018). Value structure and priorities: other-report account. Current

Issues in Personality Psychology, 6(3), 252-259.

RECEIVED 12.09.2017 · REVIEWED 01.10.2017 • ACCEPTED 04.10.2017 · PUBLISHED 18.12.2017 


\section{BACKGROUND}

Personal values are defined as trans-situational life goals that guide perception and behaviour (Schwartz, 1992; Schwartz et al., 2012). According to Schwartz (1992), basic values form a circular structure that reflects the motivations underling them. The relations among values are determined by motivational conflicts and compatibilities: Values are situated close to other values on the circle that share with them the same broad motivational goal and opposite values based on conflicting motivation. They are organised along two bipolar dimensions: openness to change vs. conservation and self-enhancement vs. self-transcendence (Schwartz, 1992). This pattern of organisation, typically found by using multidimensional scaling (MDS), has been replicated in numerous studies spanning different cultures and using a variety of questionnaires (e.g. Bilsky, Janik, \& Schwartz, 2011; Döring et al., 2015; Schwartz, 1992; Schwartz et al., 2001, 2012). Recently, the circular structure of values has also been confirmed within persons (Borg, Bardi, \& Schwartz, 2015). However, all these tests of circular structure of personal values were conducted on data collected through self-reports. There has been no study verifying the structure of values in other-ratings conducted so far.

Similarly, the hierarchy of value priorities - the importance people ascribe to certain values as guiding principles in their lives - has been studied in various groups and cultures but only on self-report data (e.g. Cieciuch, Davidov, Algesheimer, \& Schmidt, in press; Döring et al., 2015; Schwartz \& Bardi, 2001). Despite some between-group differences, Schwartz and Bardi (2001) found a pan-cultural hierarchy of values based on results from self-report inventories with benevolence, self-direction, and universalism on the top and power, tradition, and stimulation on the bottom.

In this research, for the first time we implemented an other-report approach to verify the postulate that personal values form a circular structure and to explore the hierarchy of value priorities. We also examined self-other agreement in assessing value importance.

\section{OTHER-REPORT APPROACH IN PERSONALITY}

The personality research is mostly based on self-report. However, there are problems associated with self-report measures that make them insufficient for assessing an individual's personality. For instance, people may respond in a socially desirable or self-serving way. They also apply diverse response styles that affect results from a self-report inventory (Dobewall \& Aavik, 2016). An alternative solution that overcomes these limitations is the use of ratings provided by informants who know the target well, such as family members, romantic partners, or friends. Other-ratings of personality are especially useful when self-reports cannot be obtained: for example, in cases of very young children and targets who have passed away (Dobewall \& Aavik, 2016). This method may also be useful in situations that have the highest risk of social desirability bias, for instance, in personality assessments in an organisational context (Connolly, Kavanagh, \& Viswesvaran, 2007).

Informant-rating is a part of the accepted methodological toolbox in research on personality traits. The degree of agreement between self- and other-ratings is commonly used to assess the accuracy of self-report inventories. Several studies have shown moderate self-other agreement in the Big Five personality traits. The average self-other correlations found in the meta-analysis by Connolly et al. (2007) ranged from .30 for Agreeableness to .45 for Extraversion and in the meta-analysis by Connelly and Ones (2010) from .29 for Agreeableness to .41 for Extraversion. The self-other agreement was higher when other-reports were obtained from well-acquainted informants. When the rater was a family member, the average self-other correlations ranged from .37 for Agreeableness to .48 for Extraversion (Connelly \& Ones, 2010).

\section{OTHER-REPORTS OF PERSONAL VALUES}

It is surprising that the other-report approach, accepted in studies on personality traits, has been rarely applied to studies on personal values (Dobewall, Aavik, Konstabel, Schwartz, \& Realo, 2014). Self-reports of values seem to have an even greater risk of social desirability bias than self-reports of traits because the former are more evaluative (Schwartz, 1992; Schwartz, Verkasalo, Antonovsky, \& Sagiv, 1997). Hence, other-report data usefully enrich studies on personal values.

One possible explanation for the lack of interest in the other-report approach for measuring preferences of values might be that values are considered too subjective to be judged by others (Hitlin \& Piliavin, 2004). While traits are defined as descriptions of observed patterns of behaviour, values are defined as beliefs used by individuals to judge desirability or importance of behaviour (Schwartz, 1992).

However, some recent findings suggest that values may be accurately judged in a similar way to traits. In the study by McDonalds and Letzring (2016), values were rated by participants as more visible than traits, but the item-level accuracy of judgment was higher for traits. Lee, Ashton, Pozzebon, Bourdage, and Ogunfowora (2009) found self-other agreement correlations comparable to those obtained for basic traits at the level of the two major value dimensions and in less agreement at the level of 10 basic values 
in comparison with HEXACO personality facets. Finally, Dobewall et al. (2014) showed that the four higher-order values were assessed by well-acquainted judges with accuracy similar to those for the Big Five personality traits.

Additional evidence for the usefulness of other-rating of values comes from a study conducted by Dobewall and Aavik (2016). The results indicated that informant-reports of values were as stable across time as self-rated values and other-ratings of traits.

\section{CURRENT STUDY}

In this study, we focused on assessing the agreement between self- and other-report data on values (Hypothesis 1) and verifying two (not studied before) aspects of Schwartz's value model in other-report data (Hypothesis 2 regarding the circular structure and research question regarding the hierarchy of value priorities).

Self-other agreement in values. First, we assessed the accuracy of other-ratings of preferences of four higher-order values and 19 basic values distinguished in the refined version of Schwartz et al.'s theory (2012). So far, the accuracy of other-ratings of values has been examined on higher-order values (Dobewall et al., 2014), on 10 basic values (Lee et al., 2009), and the item-level (McDonald \& Letzring, 2016), but not on 19 basic values from the refined theory.

We also analysed the level of similarity and assumed similarity between targets and observers. Similarity is defined as zero-order correlation between target self-rating and observer self-rating, and assumed similarity is defined as zero-order correlation between observer self-rating and observer rating of target (Paunonen \& Hong, 2013).

We corrected self-other agreement in two ways: for the bias caused by measurement error and for assumed similarity. The first correction was made in the way proposed by Schmidt and Hunter (1996): We divided each agreement correlation by the square root of the product of the reliability coefficients of the self- and other-ratings. To overcome the bias caused by assumed similarity, we computed a partial correlation between self- and other-ratings, controlling for observer self-rating (Paunonen \& Hong, 2013). We expected that the self-other agreement would be similar to that obtained in previous studies (Hypothesis 1).

Circular structure of values in other-report data. Second, we aimed to verify the circular structure of personal values on other-report data. This purpose was the most important for us because the postulate about circular structure of values is crucial for the Schwartz theory and has not been tested on other-report data before. Since it has been confirmed in numerous studies using diverse methodological strategies, we also expected its confirmation on data obtained from well-acquainted informants (Hypothesis 2).
Hierarchy of value priorities in other-report data. Third, we compared the hierarchy of values obtained in self-reports with the hierarchy of values obtained in other-reports. We had no specific expectation regarding possible differences between the two hierarchies. This is because the patterns of value preferences have not been examined before in other-reports. Thus we asked the research question: how similar are the two hierarchies.

\section{PARTICIPANTS AND PROCEDURE}

The study was conducted on a Polish sample of 422 people $(58.50 \%$ women; gender not provided for $4.00 \%)$. The age of participants ranged from 15 to 88 years $(M=30.02, S D=13.99$; age not provided for $5.70 \%$ ). The sample consisted of well-acquainted dyads: Both persons of each dyad provided a self-report of his/her value preferences and a report of value preferences for their partner (210 dyads; for two participants there was no self-report from their partners). All dyads were closely related: $26.10 \%$ were friends, $24.70 \%$ were spouses, $23.50 \%$ were romantic partners, $11.80 \%$ were siblings, $8.10 \%$ were parent and child, $0.90 \%$ were grandmother and grandchild, one person was assessed by an uncle, and $4.70 \%$ did not provide the type of acquaintanceship.

\section{MEASUREMENT INSTRUMENT}

For measuring value preferences, we used the revised version of the Portrait Values Questionnaire used in the original study on value model refinement (PVQ5x; Schwartz et al., 2012). We used the 48 items (two to three items measuring each of the 19 basic values) proposed by Schwartz et al. (2012). Basic values were grouped in higher-order values in a way proposed by Cieciuch, Davidov, Vecchione, Beierlein, and Schwartz (2014). Each participant filled out the same questionnaire twice: assessing how similar the participant is to the person described in items and then how similar this person is to the participant's partner. Judgments were made based on a sixpoint scale from 1 (not like me/not like my close other) to 6 (very much like me/very much like my close other). Cronbach's $\alpha$ for each value scale in self- and other-reports are presented in Table 1 in the Results section. For all analyses, value scores were mean-cantered (Schwartz et al., 2012).

\section{RESULTS}

\section{SELF-OTHER AGREEMENT}

We first examined the agreement between self- and other-reports of value preferences. In Table 1 we 
Table 1

Self-observer agreement, similarity, and assumed similarity for personal values

\begin{tabular}{|c|c|c|c|c|c|c|c|}
\hline \multirow[t]{2}{*}{ Value } & \multicolumn{2}{|c|}{ Cronbach's $\alpha$} & \multirow{2}{*}{$\begin{array}{c}\text { Self-other } \\
\text { agree- } \\
\text { ment }\end{array}$} & \multirow{2}{*}{$\begin{array}{l}\text { Self-other } \\
\text { agree- } \\
\text { ment } \\
\text { corrected } \\
\text { for } \alpha \text { 's }\end{array}$} & \multirow{2}{*}{$\begin{array}{l}\text { Similar- } \\
\text { ity }\end{array}$} & \multirow{2}{*}{$\begin{array}{c}\text { As- } \\
\text { sumed } \\
\text { similar- } \\
\text { ity }\end{array}$} & \multirow{2}{*}{$\begin{array}{l}\text { Self-other } \\
\text { agree- } \\
\text { ment cor- } \\
\text { rected for } \\
\text { similarity }\end{array}$} \\
\hline & $\begin{array}{l}\text { Self- } \\
\text { reports }\end{array}$ & $\begin{array}{l}\text { Other- } \\
\text { reports }\end{array}$ & & & & & \\
\hline \multicolumn{8}{|l|}{ Basic values } \\
\hline Self-direction-thought & .61 & .64 & .37 & .59 & .04 & .18 & .37 \\
\hline Self-direction-action & .61 & .70 & .31 & .47 & .16 & .22 & .29 \\
\hline Stimulation & .64 & .60 & .34 & .55 & .16 & .16 & .32 \\
\hline Hedonism & .65 & .71 & .53 & .78 & .12 & .13 & .53 \\
\hline Achievement & .67 & .66 & .38 & .57 & .14 & .16 & .37 \\
\hline Power-resources & .75 & .79 & .49 & .64 & .17 & .19 & .48 \\
\hline Power-dominance & .69 & .78 & .34 & .46 & .12 & .11 & .34 \\
\hline Face & .50 & .48 & .17 & .35 & .12 & .10 & .16 \\
\hline Security-personal & .71 & .75 & .41 & .56 & .11 & .20 & .40 \\
\hline Security-societal & .57 & .68 & .21 & .34 & .05 & .09 & .22 \\
\hline Conformity-rules & .79 & .83 & .41 & .51 & .13 & .19 & .40 \\
\hline Conformity-interpersonal & .72 & .77 & .35 & .47 & -.03 & .01 & .36 \\
\hline Tradition & .77 & .84 & .51 & .63 & .15 & .20 & .50 \\
\hline Humility & .48 & .49 & .27 & .56 & .00 & .13 & .27 \\
\hline Benevolence-dependability & .64 & .74 & .20 & .29 & -.01 & .02 & .20 \\
\hline Benevolence-caring & .75 & .77 & .38 & .50 & .09 & .09 & .38 \\
\hline Universalism-concern & .70 & .77 & .39 & .53 & .11 & .14 & .38 \\
\hline Universalism-nature & .87 & .87 & .36 & .41 & .13 & .15 & .36 \\
\hline Universalism-tolerance & .59 & .66 & .23 & .37 & .04 & .06 & .22 \\
\hline \multicolumn{8}{|l|}{ Higher-order values } \\
\hline Openness to change & .78 & .81 & .47 & .59 & .13 & .18 & .46 \\
\hline Conservation & .84 & .88 & .56 & .65 & .18 & .16 & .56 \\
\hline Self-transcendence & .83 & .88 & .44 & .51 & .14 & .15 & .44 \\
\hline Self-enhancement & .69 & .72 & .47 & .67 & .16 & .17 & .46 \\
\hline
\end{tabular}

Note. Openness to change - mean of hedonism, stimulation, self-direction-action, and self-direction-thought; conservation mean of humility, conformity-interpersonal, conformity-rules, tradition, security-societal, security-personal, and face; self-transcendence - mean of benevolence-caring, benevolence-dependability, universalism-nature, universalism-tolerance, and universalism-concern; self-enhancement - mean of achievement, power-resources, and power-dominance.

presented Cronbach's $\alpha$ for each of 19 basic values and for four higher-order values, separately for selfand other-reports; then correlation coefficients for self-other agreement; correlation coefficients corrected for measurement bias (Schmidt \& Hunter, 1996); and after that, coefficients of similarity, assumed similarity, and correlation coefficients for self-other agreement corrected for assumed similarity (partial correlation between target self-rating and observer rating of target, controlling for observer self-rating).
Cronbach's $\alpha$ for basic values ranged from .48 (humility) to .87 (universalism-nature) in self-reports and from .48 (face) to .87 (universalism-nature) in other-reports. Alphas for higher-order values ranged from .69 (self-enhancement) to .84 (conservation) in self-reports and from .72 (self-enhancement) to .88 (conservation and self-transcendence) in other-reports. Some alphas were low due to the very short size of the scales (only two items long). Using Schmidt's and Hunter's (1996) correction for measurement bias somehow resolved this issue. 
Self-other agreement coefficients for higher-order values were similar to those obtained in Dobewall et al.'s (2014) study (ranged from .43 to .50), considered by them satisfactory as not substantially different from those of the Big Five personality traits. Agreement coefficients for 19 basic values were similar (mean zero-order agreement $=.35)$ to those for 10 basic values (mean zero-order agreement $=.29$ ) obtained in the study by Lee et al. (2009) and that for NEO-PI-R facets (mean zero-order agreement $=.35$ ) obtained in the study by Paunonen and Hong (2013). These findings support Hypothesis 1.

The level of similarity (zero-order correlation between target and observer self-reports) in our sample was relatively low. The coefficients of assumed similarity (zero-order correlation between observer rating of target and observer self-report) were not substantially different from coefficients of similarity. This indicated that assumed similarity actually reflected the true similarity: Participants in dyads knew each other well and were aware of existing similarities (Paunonen \& Hong, 2013). Because the level of similarity was low, the agreement coefficients did not change substantially after correction for similarity.

\section{THE STRUCTURE OF VALUES IN OTHER-REPORTS}

We tested the circular structure of values by two-dimensional ordinal MDS, using IBM SPSS Statistics 22 software. We included measures from both self- and other-reports. The results are presented in Figure 1.

The observed order of the 19 values around the circle largely corresponded with the theoretical order, supporting Hypothesis 2. Nevertheless, there were a few deviations. In both self- and other-report data, the positions of benevolence and universalism reversed. The same deviation was found in Schwartz et al.'s (2012) analyses. Also, in both self- and other-reports, universalism-nature was situated next to conformity-rules. In other-reports there were a couple of smaller deviations not replicated in self-report data: Three pairs of values were reversed, namely: power-resources with power-dominance, tradition with conformity-rules, and humility with conformity-interpersonal; benevolence-care was combined with benevolence-dependability.

\section{THE HIERARCHY OF VALUES IN OTHER-REPORTS}

In Table 2 we present a comparison of two hierarchies of values: based on self-reports and based on other-reports. It turned out that the hierarchies of 19 basic values were similar to each other. The first five and the last five values in both hierarchies were the same.
On the top of the hierarchies also the order of values was identical. The Spearman rank correlation between the two hierarchies was $.95(p<.001)$. However, there were some differences between the two hierarchies. In the middle of the hierarchies, in other-reports achievement was assessed as more important than in self-reports, whereas security-societal was assessed as more important in self-reports. On the bottom of the hierarchies, tradition, humility, and power-resources were situated higher in other-reports and universalism-tolerance, conformity-interpersonal, and universalism-nature were situated lower than in self-reports. In comparison to the level of higher-order values, there was one substantial difference between the two hierarchies: Self-enhancement values were rated as more important in other-reports (with the mean close to 0 ) than in self-reports (with the mean much lower than 0 ).

The patterns of value priorities in both hierarchies were consistent with those found by Schwartz and Bardi (2001) across cultures: Benevolence and self-direction were most important, and power, conformity, and stimulation were least important. The only difference was that universalism was not among the most important values in our sample.

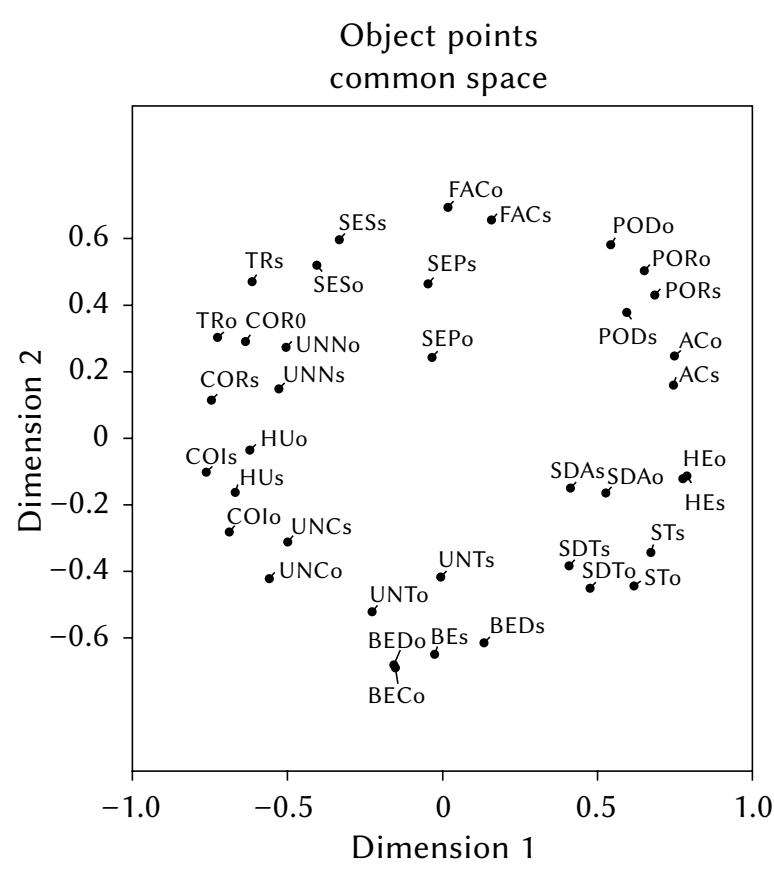

Note. SDT - self-direction-thought; SDA - self-direction-action; ST - stimulation; HE - hedonism; AC - achievement; POD - powerdominance; POR - power-resources; FAC - face; SEP - securitypersonal; SES - security-societal; COR - conformity-rules; COI - conformity-interpersonal; TR - tradition; HU - humility; BED - benevolence-dependability; BEC - benevolence-caring; UNC universalism-concern; UNN - universalism-nature; UNT - universalism-tolerance.

Figure 1. Multidemensional scaling of 19 basic values measured in self-report (all the variables with „s" at the end of the name, e.g. SDTs) and in other-report (all the variables with "o" at the end of the name, e.g. SDTo). 
Ewa Skimina, Jan Cieciuch

Table 2

The comparison of hierarchies of value importance between self-and other-reports

\begin{tabular}{|c|c|c|c|}
\hline \multicolumn{2}{|l|}{ Self-report } & \multicolumn{2}{|c|}{ Other-report } \\
\hline Value & $M$ & Value & $M$ \\
\hline \multicolumn{4}{|l|}{ Basic values } \\
\hline Benevolence-caring & .99 & Benevolence-caring & $.81 \downarrow$ \\
\hline Self-direction-action & .63 & Self-direction-action & .64 \\
\hline Benevolence-dependability & .57 & Benevolence-dependability & .53 \\
\hline Security-personal & .56 & Security-personal & .47 \\
\hline Self-direction-thought & .44 & Self-direction-thought & $.33 \downarrow$ \\
\hline Security-societal & .21 & Achievement & $.16 \uparrow$ \\
\hline Universalism-concern & .21 & Hedonism & .15 \\
\hline Hedonism & .09 & Universalism-concern & $.09 \downarrow$ \\
\hline Achievement & .02 & Security-societal & $.00 \downarrow$ \\
\hline Universalism-tolerance & -.02 & Face & $-.02 \uparrow$ \\
\hline Face & -.14 & Tradition & $-.17 \uparrow$ \\
\hline Conformity-interpersonal & -.24 & Universalism-tolerance & $-.18 \downarrow$ \\
\hline Tradition & -.26 & Stimulation & -.20 \\
\hline Stimulation & -.29 & Conformity-interpersonal & -.32 \\
\hline Universalism-nature & -.49 & Power-resources & $-.38 \uparrow$ \\
\hline Conformity-rules & -.66 & Humility & $-.54 \uparrow$ \\
\hline Power-resources & -.67 & Conformity-rules & -.55 \\
\hline Humility & -.73 & Power-dominance & $-.59 \uparrow$ \\
\hline Power-dominance & -.95 & Universalism-nature & $-.75 \downarrow$ \\
\hline \multicolumn{4}{|l|}{ Higher-order values } \\
\hline Openness to change & .37 & Openness to change & .35 \\
\hline Self-transcendence & .25 & Self-transcendence & $.10 \downarrow$ \\
\hline Conservation & -.16 & Self-enhancement & $-.01 \uparrow$ \\
\hline Self-enhancement & -.20 & Conservation & -.16 \\
\hline
\end{tabular}

\section{DISCUSSION}

For the first time, we used an other-report approach for measuring the preferences of personal values not only to assess its accuracy but to test the circular structure of values and explore the patterns of value priorities. We analysed self- and other-reports of preferences of 19 basic and four higher-order values provided by well-acquainted dyads.

The results of MDS confirmed that 19 basic values measured via other-reports formed a circular structure. The order of values around the motivational circle slightly deviated from the theorised one, but was largely consistent with those for self-reports obtained in the same study. The deviations from the theorised order of values were not more substantial than reported in other studies conducted on self-report data (Schwartz et al., 2012).

Schwartz's (1992; Schwartz et al., 2012) postulate about the organisation of values around the motivational circle has been supported by self-report data collected by using various inventories (based on the Schwartz theory and constructed by a lexical method; e.g. Borg, Dobewall, \& Aavik, 2016; Schwartz, 1992), as well as among and within persons (Borg et al., 2015). Now, the results of this study provide another piece of evidence for the circular structure of personal values: other-report data.

Our findings indicate that other-reports of value preferences may serve as a valuable contribution to 
self-reports. The reliability of other-reports of values in this study was at the same level as reliability of self-reports, regarding Cronbach's $\alpha$ coefficients. The accuracy of other-ratings assessed as self-other agreement was comparable with those for personality traits obtained in other studies (Dobewall et al., 2014; Paunonen \& Hong, 2013). Assumed similarity was relatively low and reflected the true similarity between target and observer.

The hierarchy of values based on other-reports was largely consistent with that based on self-reports. The first five and the last five values in both hierarchies were the same. In general, in both self- and other-reports openness to change values were rated as most important, followed by self-transcendence values. This similarity between the two hierarchies indicates that self-ratings of value priorities are not as largely biased by social desirability as it might be supposed, at least in comparison with ratings provided by well-acquainted others. The same conclusion was reached by Schwartz et al. (1997), who analysed the relationships between socially desirable responding and self-reported value ratings.

However, there were some differences between the two hierarchies. In self-report self-enhancement values were least important preceded by conservation values, while in other-report conservation values were assessed as least important. Self-enhancement values were rated as more important and self-transcendence values were rated as less important in other- than in self-reports. Self-enhancement values represent personal focus and self-transcendence represent social focus, thus the former might be considered less desirable than the latter (Schwartz et al., 1997). This is consistent with the finding that self-other agreement for some values is higher than for others. McDonald and Letzring (2016) showed that basic values differ in visibility and evaluative strength, which affects self-other agreement. They suggested that some values might be more accurately judged by the self (less observable), whereas other values (more observable and less evaluative) might be more accurately judged by others. Some evidence for this idea may be found in the results of this study. Achievement (one of the self-enhancement values), judged as one of the most visible values in the study by McDonald and Letzring, was not among the values of highest self-other agreement in their study or in our study. Achievement also took different positions in hierarchies based on selfand other-reports. It is possible that achievement is one of those values judged better by observers than by the self. Further examination of this issue might be a suggestion for future research. It can be made, for instance, by comparison of self- and other-ratings of achievement importance as predictors of objective behavioral criterion. Assessing one's own conservation values as more important than self-enhancement values and other's conservation values as less important than their self-enhancement values can also be interpreted in terms of agentic-communion dimension of perception (Abele \& Wojciszke, 2014).

One limitation of this study is that we used other-reports from only one informant, while it is advised to have several raters (Rauthmann, 2017). However, despite this fact, the level of accuracy we obtained was similar to that from the study by Dobewall et al. (2014) with two informants for each target. The second limitation is that the informants were recruited by the targets, and such informants might tend to portray them in an overly positive way (the letter of recommendation effect; Leising, Erbs, \& Fritz, 2010). Another limitation is that the other-report was made by participants always after self-report, which might bias the similarity.

\section{CONCLUSIONS}

We conclude that the value circle postulated by the Schwartz theory (Schwartz, 1992; Schwartz et al., 2012) exists not only in self-report data but also in other-report data. The hierarchies of values in self-ratings and in other-ratings are largely consistent, which indicates that self-report of values is not as biased by social desirability as we might suppose. The level of congruence between self- and other-ratings suggests that both measurement approaches may be useful in studies on personal values and that they contribute to each other.

\section{ACKNOWLEDGMENT}

The work was supported by grant 2014/14/M/HS6/ 00919 from the National Science Centre, Poland.

\section{REFERENCES}

Abele, A. E., \& Wojciszke, B. (2014). Communal and agentic content in social cognition: A Dual Perspective Model. In J. M. Olson \& M. P. Zanna (Eds.), Advances in Experimental Social Psychology (Vol. 50, pp. 195-255). DOI: 10.1016/B978-0-12800284-1.00004-7

Bilsky, W., Janik, M., \& Schwartz, S. H. (2011). The structural organization of human values - Evidence from three rounds of the European Social Survey (ESS). Journal of Cross-Cultural Psychology, 42, 759-776. DOI: 10.1177/0022022110362757

Borg, I., Bardi, A., \& Schwartz, S. H. (2015). Does the value circle exist within persons or only across persons? Journal of Personality, 85, 151-162. DOI: 10.1111/jopy. 12228

Borg, I., Dobewall, H., \& Aavik, T. (2016). Personal values and their structure under universal and lexical approaches. Personality and Individual Differences, 96, 70-77. DOI: 10.1016/j.paid.2016.02.071 
Cieciuch, J., Davidov, E., Algesheimer, R., \& Schmidt, P. (in press). Testing for approximate measurement invariance of human values in the European Social Survey. Sociological Methods \& Research. DOI: 10.1177/0049124117701478

Cieciuch, J., Davidov, E., Vecchione, M., Beierlein, C., \& Schwartz, S. H. (2014). The cross-national invariance properties of a new scale to measure 19 basic human values. A test across eight countries. Journal of Cross-Cultural Psychology, 45, 764-779. DOI: $10.1177 / 0022022114527348$

Connelly, B. S., \& Ones, D. S. (2010). An other perspective on personality: Meta-analytic integration of observers' accuracy and predictive validity. Psychological Bulletin, 136, 1092-1122. DOI: 10.1037/a0021212

Connolly, J. J., Kavanagh, E. J., \& Viswesvaran, C. (2007). The convergent validity between self and observer ratings of personality: A meta-analytic review. International Journal of Selection and Assessment, 15, 110-117. DOI: 10.1111/j.14682389.2007.00371.x

Dobewall, H., Aavik, T., Konstabel, K., Schwartz, S. H., \& Realo, A. (2014). A comparison of self-other agreement in personal values versus the Big Five personality traits. Journal of Research in Personality, 50, 1-10. DOI: 10.1016/j.jrp.2014.01.004

Dobewall, H., \& Aavik, T. (2016). Rank-order consistency and profile stability of self-and informant-reports of personal values in comparison to personality traits. Journal of Individual Differences, 37, 40-48. DOI: 10.1027/1614-0001/a000186

Döring, A. K., Schwartz, S. H., Cieciuch, J., Groenen, P. J. F., Glatzel, J., Harasimczuk, J., ...Bilsky, W. (2015). Cross-cultural evidence of value structures and priorities in childhood. British Journal of Psychology, 106, 675-699. DOI: 10.1111/bjop.12116

Hitlin, S., \& Piliavin, J. A. (2004). Values: Reviving a dormant concept. Annual Review of Sociology, 30, 359393. DOI: 10.1146/annurev.soc.30.012703.110640

Lee, K., Ashton, M. C., Pozzebon, J. A., Bourdage, J. S., \& Ogunfowora, B. (2009). Similarity and assumed similarity in personality reports of well-acquainted persons. Journal of Personality and Social Psychology, 96, 460-472. DOI: 10.1037/a0014059

Leising, D., Erbs, J., \& Fritz, U. (2010). The letter of recommendation effect in informant ratings of personality. Journal of Personality and Social Psychology, 4, 668-682. DOI: 10.1037/a0018771

McDonald, J. S., \& Letzring, T. D. (2016). Judging personal values and personality traits: Accuracy and its relation to visibility. Journal of $R e-$ search in Personality, 65, 140-151. DOI: 10.1016/j. jrp.2016.10.009

Paunonen, S. V., \& Hong, R. Y. (2013). The many faces of assumed similarity in perceptions of personality. Journal of Research in Personality, 47, 800-815. DOI: $10.1016 /$ j.jrp.2013.08.007
Rauthmann, J. F. (2017). What are other-rated scales composed of? Sources of measurement error and true trait variance in other-ratings of the Big Five. Journal of Research in Personality, 70, 45-55. DOI: 10.1016/j.jrp.2017.05.002

Schmidt, F. L., \& Hunter, J. E. (1996). Measurement error in psychological research: Lessons from 26 research scenarios. Psychological Methods, 1, 199-223.

Schwartz, S. H. (1992). Universals in the content and structure of values: Theory and empirical tests in 20 countries. In M. Zanna (Ed.), Advances in experimental social psychology (Vol. 25, pp. 1-65). New York, NY: Academic Press.

Schwartz, S. H., \& Bardi, A. (2001). Value hierarchies across cultures: Taking a similarities perspective. Journal of Cross-Cultural Psychology, 32, 268-290. DOI: $10.1177 / 0022022101032003002$

Schwartz, S. H., Cieciuch, J.,Vecchione, M., Davidov, E., Fischer, R., Beierlein, C., ...Konty, M. (2012). Refining the theory of basic individual values. Journal of Personality and Social Psychology, 103, 663-688. DOI: $10.1037 / \mathrm{a} 0029393$

Schwartz, S. H., Melech, G., Lehmann, A., Burgess, S., Harris, M., \& Owens, V. (2001). Extending the cross-cultural validity of the Theory of Basic Human Values with a different method of measurement. Journal of Cross-Cultural Psychology, 32, 519-542. DOI: 10.1177/0022022101032005001

Schwartz, S. H., Verkasalo, M., Antonovsky, A., \& Sagiv, L. (1997). Value priorities and social desirability: Much substance, some style. British Journal of Social Psychology, 36, 3-18. DOI: 10.1111/j.20448309.1997.tb01115.x 